\title{
Meet the New Hormones and Cancer Editorial Team: Donald P. McDonnell, Associate Editor
}

Published online: 16 January 2015

(C) Springer Science+Business Media New York 2015

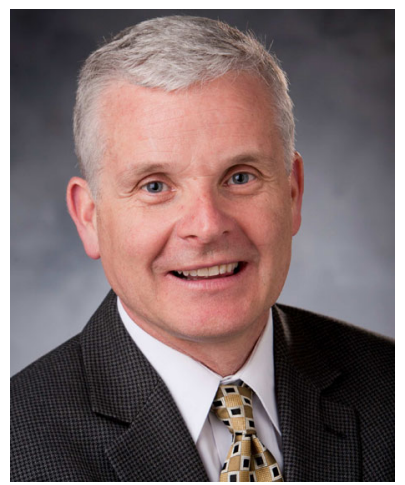

Donald P. McDonnell, Ph.D., is the Glaxo-Wellcome Professor of Molecular Cancer Biology and Chairman of the Department of Pharmacology and Cancer Biology at Duke University School of Medicine. In addition, he serves as Co-Director of the Women's Cancer Program within the Duke Cancer Institute.

Dr. McDonnell obtained a Degree in Biochemistry from the National University of Ireland (Galway) in 1983. He then moved to Baylor College of Medicine, Houston, Texas, where in 1988, he obtained a PhD under the mentorship of Dr. Bert O'Malley. It was during this time that he cloned the cDNA for the vitamin D receptor and performed a series of experiments that led to the conclusion that this receptor was related in both sequence and function to the classical steroid receptors. $\mathrm{He}$ subsequently spent a year as a postdoctoral fellow at SmithKline Pharmaceuticals in Philadelphia where he developed an interest in studying the molecular pharmacology of nuclear receptors. The development of mechanism-based screens for nuclear receptor agonists and antagonists was the focus of his research when he moved back to Baylor College of Medicine as an Assistant Professor of Cell Biology. Given this interest in drug discovery, it was not a surprise that in 1991 he again returned to the private sector as Director and Head of Molecular Biology at Ligand Pharmaceuticals in San Diego. After three very exciting years in industry, he moved to Duke where his work has focused on the genetic and pharmacological dissection of the nuclear receptor signal transduction pathways. The insights from this work have led to the discovery and development of novel estrogen and androgen receptor modulators, some of which have advanced to the clinic and are being evaluated as treatments for a variety of endocrinopathies.

Dr. McDonnell has received numerous investigator awards; the most notable being the Roy E. Greep, Weitzman, and Ernst Oppenheimer Awards from the Endocrine Society, ASPET's John J. Abel Award, the Pharmacia-ASPET Award for Experimental Therapeutics and the NAMS SERM Research Award. He is an Honorary Fellow of the Royal College of Physicians, Ireland. Dr. McDonnell has published over 240 articles on the molecular pharmacology of nuclear hormone receptors. Currently, he sits on the editorial boards of Oncogene, Trends in Endocrinology and Metabolism and Molecular Endocrinology. Dr. McDonnell has substantial editorial experience, notably having served as Associate Editor for Molecular Endocrinology for the Endocrine Society from 2004 until 2008. He is enthusiastic about starting work on Hormones and Cancer. 